Bach, V.; Berger, M.; Forin, S.; Finkbeiner, M.

\title{
Comprehensive approach for evaluating different resource types - Case study of abiotic and biotic resource use assessment methodologies
}

Journal article | Accepted manuscript (Postprint)

This version is available at https://doi.org/10.14279/depositonce-8558

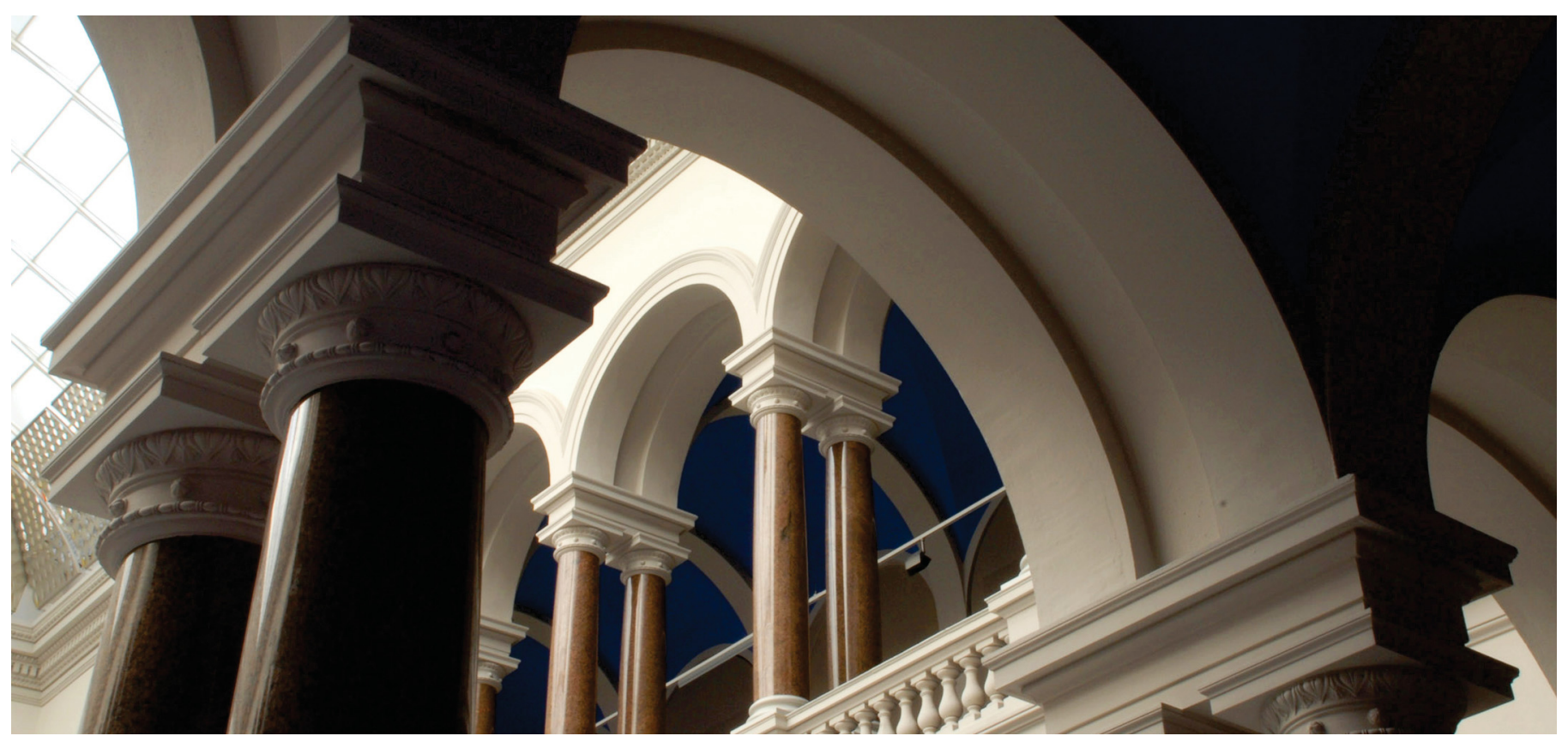

Bach, V., Berger, M., Forin, S., \& Finkbeiner, M. (2018). Comprehensive approach for evaluating different resource types - Case study of abiotic and biotic resource use assessment methodologies. Ecological Indicators, 87, 314-322. https://doi.org/10.1016/j.ecolind.2017.12.049 


\title{
Comprehensive approach for evaluating different resource types - Case study of abiotic and biotic resource use assessment methodologies
}

\author{
Vanessa Bach ${ }^{1}$, Markus Berger ${ }^{1}$, Silvia Forin ${ }^{1}$ and Matthias Finkbeiner ${ }^{1}$ \\ ${ }^{1}$ Technische Universität Berlin, Chair of Sustainable Engineering, Straße des 17. Juni 135, 10623 Berlin, Germany \\ * Corresponding author: vanessa.bach@tu-berlin.de
}

\begin{abstract}
Due to steadily increasing resource demand and accompanying raising public awareness, a variety of assessment methodologies evaluating resource use and its consequences were published in the last years. Existing methodologies are typically developed considering the specific characteristics of one particular resource type and as consequence are not suitable for cross-cutting assessment of different resource types. This paper proposes an 8-step approach and provides a user-friendly flow chart for combining different resource use assessment methodologies allowing for a consistent assessment of product systems using different resource types. The first steps evaluate if the considered dimensions, categories, indicators, indicator models and underlying data are consistent. When this is the case, they can be included in the combined methodology without further adjustments. Differences are identified simultaneously and addressed in the subsequent steps. Within the steps guidance is provided on how the dimensions, categories and indicators of the methodologies can be adjusted to fit in the combined methodology. In a case study the proposed approach is applied to two methodologies developed by the authors assessing abiotic (ESSENZ method) and biotic resources and raw materials (BIRD method). The ESSENZ method consists of four dimensions, which are quantified by overall 21 categories and indicators. The BIRD method takes into account five dimensions and 24 corresponding categories and indicators. As none of the considered dimension of the two methodologies match, comparison of the considered resource types as well as application in a case study is not possible. By applying the proposed approach all five dimensions and 25 of the overall 27 categories and indicators can be integrated in the combined approach for a consistent assessment of abiotic and biotic resources and raw materials. The obtained combined methodology is then applied to three shelves made out of metal, wood and plastic. It could be shown that the introduced approach provides meaningful guidance on how to combine different resource use assessment methodologies and increases the findings gained from a combined and consistent assessment.
\end{abstract}

\section{Keywords}

resource assessment methodology, resource use, life cycle impact assessment, ESSENZ, BIRD

\section{Highlights}

- The proposed approach provides guidance on how different resource assessment methodologies can be combined.

- The methodologies ESSENZ (for abiotic resources) and BIRD (for biotic resources) are combined successfully.

- Applying a combined methodology allows for a consistent assessment of different resource types. 


\section{Introduction}

Continuing global industrial and technological development has steadily increased the demand for resources. Their use has therefore been a topic of discussion throughout the last decades with regard to competition on resources (availability of resources and raw materials as well as related vulnerabilities of companies and countries) and corresponding environmental (e. g. climate change) as well as social aspects (e. g. working conditions). With that also the need to assess resource use and its related impacts has been growing. This led to the publication of a variety of assessment methodologies for evaluating resource use (mostly for abiotic resources and raw materials (e. g. Schneider et al. (2016), van Oers and Guinée (2016) and Berger and Sonderegger (2017)) as well as water (e. g. Pfister et al. (2009), Berger et al. (2014) and Núñez et al. (2016)), but also for biotic resources and raw materials (e. g. Oakdene Hollins(2014) and Bach et al. (2017)) as well as land (e. g. Beck et al. (2010) and Koellner et al. (2013)). So far, almost all of these methodologies are developed explicitly for one type of resource only. Hence, methods developed to assess the use of abiotic resources cannot be applied to assess biotic resources and vice versa.

The term resource refers to entities, which can be extracted from nature and transferred to the anthroposphere. This includes abiotic and biotic resources, abiotic and biotic raw materials as well as water, land, and the natural environment (European Commission 2005; Schneider et al. 2016; Sonderegger et al. 2017). Based on the specific characteristics of the considered resource or raw material, relevant aspects (and corresponding indicators) are defined. For instance, availability constraints are mostly associated with abiotic resources and raw materials (Dewulf et al. 2016), renewability rates with biotic resources (Crenna and Sala 2017), scarcity for water (Pfister et al. 2017), etc. The development of methodologies for specific resource types allows accounting for relevant aspects in a consistent way. However, existing methodologies use neither equal nor complementary indicators. This makes it challenging to assess different resource types in a consistent way. Often only few indicators are applied for the comparison of different resource types (e. g. as shown by Ritthoff et al. (2002); Zabalza Bribián et al. (2011), Alvarenga et al. (2013) and Klinglmair et al. (2014)), which do not comprehensively reflect all aspects of resource use and its related implications and therefore do not enable an adequate assessment. For example, even though biofuels are made from renewable resources, which cannot be consumed in the same way as fossil fuels can, their use is limited by land and phosphorus availability (Hein and Leemans 2012; Rulli et al. 2016; March et al. 2016). However, currently phosphorus and land use are often not addressed in the assessment of biotic materials (Rack et al. 2013; Finkbeiner et al. 2014; Mousavi-Avval et al. 2017). The lack of equal as well as complementary indicators to assess different resource types shows the need for guidance on how to combine different methodologies for adequately evaluating and comparing different resource types.

This methodological gap is addressed in this paper, which has the aim of providing guidance for combining different resource use assessment methodologies and thus achieving a more comprehensive assessment and adequate comparison of different resource types.

In the next section, the proposed approach including a user-friendly flow chart for easy application is introduced (section 2). Next, the approach is applied to a case study (section 3), where two methodologies developed by the authors (one for the assessment of abiotic resources and raw materials and one for biotic ones) are combined according to the proposed approach. The combined methodology is then applied for an exemplary product system considering three sorts of shelves (made out of wood, plastic and metal). Further, challenges of the proposed approach are discussed (section 4) and conclusions are drawn (section 5).

\section{Method}

In this section the proposed approach to combine methodologies evaluating different resource types is introduced. As shown in Figure 1 overall eight steps are proposed, which are described in detail in the following.

To apply the proposed approach it is assumed that the practitioner is familiar with the methodologies and aware of their shortcomings. The proposed approach can be applied for methodologies assessing resource use, independently from the number of aspects and indicators considered. However, as the goal of the approach is to combine multi indicator methodologies, the focus is on methodologies taking into account several categories and indicators (e. g. Graedel et al. (2012), European Commission (2014) and Bach et al. (2016a)) instead of methodologies considering only one or few indicators (e. g. Oers et al. (2002), Valero et al. (2014) and Finnveden et al. (2016)). As indicators are designed differently depending on the level considered (micro (product), meso (company) or macro (company) level), methodologies can only be combined when they address the same level. 
The approach can be applied to combine two or more methodologies. For the sake of simplicity, this paper describes the combination of two methodologies.

The approach is presented as a flow chart to enhance applicability (see Figure 1). Every step is phrased as a question, which can only be answered with "yes" or "no". Depending on the answer, the user is guided to the subsequent step. If the question is answered with "yes", the requirements formulated in this step are fulfilled (e. g. the same dimensions are taken into account).

If the question is answered with "no", the requirements are not met. The approach has to be carried out until one of the four ending points for all considered dimensions, categories and indicators is reached.

Following, the individual steps of the proposed approach are described in detail. First, the procedure is described for steps fulfilling the formulated requirements (questions are all answered with "yes"). In this case, the considered methodologies take into account equal dimensions, categories and indicators as well as underlying models and data. Next, the procedure is described when the formulated requirements are not fulfilled and the questions are therefore answered with "no".

In step 1a the question "Are the same dimensions taken into account?" is addressed. Possible dimensions could be the classical sustainability dimension: environmental, economic and social (Giddings et al. 2002) as well newly developed dimensions like criticality (Sonnemann et al. 2015). When the same dimension are included (the question of step 1a can be answered with "yes") the approach continues with step 2a, where the question "Are the same categories considered within equal dimensions?" is addressed. For example: human health impacts are often considered as part of the environmental dimension, because impacts are determined as part of an Life Cycle Assessment (LCA) case study. Sometimes though these categories are seen as part of human well-being and are placed in the social dimension. When the same categories are addressed, they are further analyzed in step 3a, where the question "Are the same indicators applied within equal categories?" is addressed. For example: The category acidification can be quantified within LCA by establishing the category indicator hydrogen ion release as done by Bare (2002) in the TRACl (Tool for the Reduction and Assessment of Chemical and other environmental Impacts) method or by Hauschild and Wenzel (1998) and Huijbregts (1999) in CML-IA (Impact Assessment methodology by Instititute of Environmental Sciences - Universiteit Leiden) (Guinée et al. 2002). Are the same indicators used, it is evaluated next if the underlying models (step 4a: Are the same models applied for each indicator?) and data (step 5a: Are the same data applied for each indicator?) are consistent. For example: For determining the category acidification the methods by Bare (2002) and Hauschild and Wenzel (1998) and Huijbregts (1999) apply the same category indicator. However, the underlying models are different. TRACI considers emission release and distribution within the US, whereas CML-IA applies European release and distribution pathways. This means that the underlying data are different. For indicators that apply the same models and data and are further addressing the same categories and dimensions, one of the four ending points ("Dimensions, categories and indicators are included in the combined methodology") is reached: these indicators can be used within the combined methodology without further adjustments.

However, as methodologies often do not consider the same dimensions, categories and indicators as well as underlying models and data, guidance is needed on how they can be adapted to be combined in a consistent way. As mentioned, carrying out the steps 1 a to 5 a reveals differences in dimensions, categories, indicators, models and data. Further steps analyze whether additional dimensions, categories and indicators of the examined methodologies can be adjusted to be applied in a combined methodology.

Differences identified in the first step (1a) refer to discrepancies of the established dimensions (e. g. one methodology only considers availability of resources, whereas the other methodology also takes into account social implications). In this case, the approach continues with step $1 \mathrm{~b}$, where the question "Do different dimensions address the same aspects?" has to be answered. Is the answer "yes", the dimensions and associated categories should be renamed and/or rearranged accordingly. For example: the assessment of human health impacts could be shifted from the environmental dimension to the social dimension to be able to establish the social dimension. Before dimensions and categories are renamed and rearranged it should be decided, which of the considered methodologies is selected as the standard framework. For the dimensions which can be renamed and/or rearranged the approach continues with step $2 \mathrm{a}$, the categories of other dimensions are further analyzed in step 6 (which will be explained later on). 
In step $2 \mathrm{~b}$ the question "Do different categories address the same aspect?" is addressed. When different categories address the same aspect, they can be renamed accordingly. For example: categories named company concentration and producer diversity address the same aspect (concentration of raw material producing companies) (Achzet and Helbig 2013) and thus could be renamed by introducing a new terminology or by renaming one of the categories accordingly. For categories which can be renamed, the approach continues with step 3a, otherwise categories are analyzed further in step 6 . 


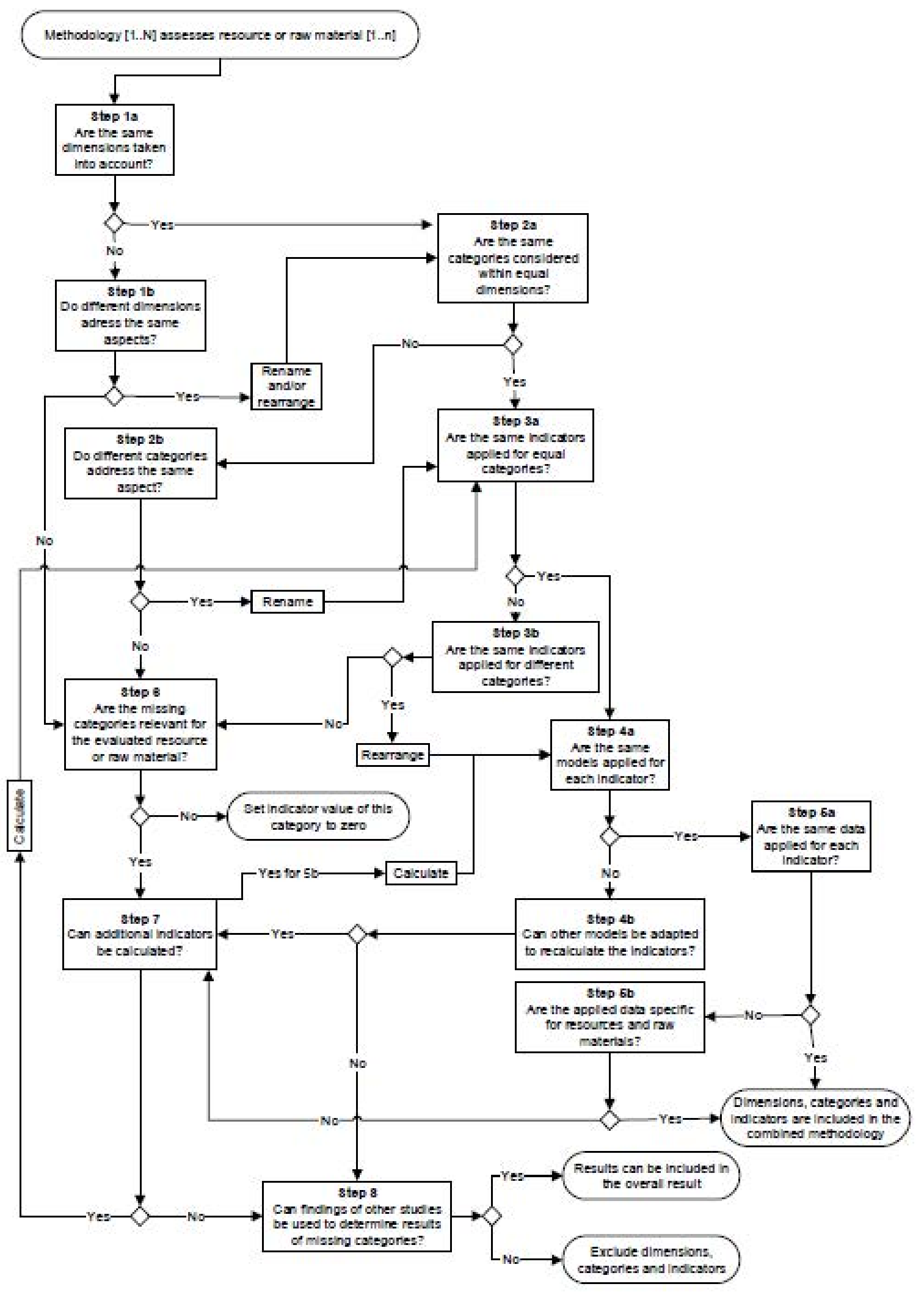

Figure 1: Proposed approach to combine methodologies evaluating different resource types 
Within Step 3b the question "Are the same indicators applied for different categories?" is addressed when step $3 a$ is answered with "no". Therefore, the applied indicators are compared across categories (and dimensions). For example, the indicator static range is referred to as mining capacity within Bach et al. (2016a) and as depletion time within Graedel et al. (2012), but is determined according to the same principle and addresses the same aspect (resources currently economically extractable considering technological state of the art). Are indicators identical, they can be rearranged accordingly and are analyzed in step 4a. Different indicators are further addressed in step 6.

In step 4a the indicators are analyzed with regard to their underlying models. If the same models are applied, the approach continues with step 5a. Different models are further analyzed regarding possible adaptations in step $4 \mathrm{~b}$. To determine if a model can be adopted, it is identified whether the model is specific for a resources type. If it is specific for a resources type, model adjustments are difficult and often not possible. For example: abiotic resource depletion cannot be determined by the indicator measuring biotic resource depletion and vice versa. If the underlying model is not specifically established for a resource type, applying another model is often possible. This is the case for the category acidification: resource use specific acidification impacts are determined by considering specific inventory data, but the underlying model does not take into account which resource type is evaluated. If adaptation of the models is possible, the approach continues with step 7, otherwise step 8 is addressed (both steps will be explained later).

Besides the models, also the used data has to be consistent (evaluated in step 5a). When different data is used, the question of step $5 b$ "Are the data specific for resources and raw materials?" is addressed. An example for resource and raw material specific data is the global production data used for the determination of socioeconomic availability constraints. The source of this data differs depending on the considered material: for abiotic resources and raw materials data provided by United States Geological Survey (USGS) (2015) is applied often, whereas for biotic raw resources and raw materials data provided by Food and Agriculture Organization of the United Nations (FAO) (2015) is used. When underlying data is specific for resources and raw materials, application of different data sources still facilitates adequate comparison and the indicators can be included in the combined methodology (same ending point as before with step 5a). If the underlying data is not resource and raw material specific, the same data sources have to be used and the approach continues with step 7. An example for data not specific for resources and raw materials are indicators like the Worldwide Governance Indicators (Kaufmann et al. 2011; World Bank Group 2013) to determine political stability of the dimension socioeconomic availability. The stability of the politic system of a country is the same whether abiotic or biotic resources are extracted. Other conditions related to the extraction of specific resource types influenced by the political situation are taken into account by considering additional categories such as feasibility of mining explorations.

Following, step 6 addresses the question "Are the missing categories relevant for the evaluated resource or raw material?". This step considers categories addressing different dimensions (from step 1b), different aspects (from step $2 b$ ) as well as different indicators (from step $3 b$ ). Is the category determined as not relevant, the indicator value can be set to zero and another ending point of the approach is reached "Set indicator value of this category to zero"). For example: the regeneration rate is a relevant aspect for biotic resources but not for abiotic ones, because abiotic resources are formed over very long geological periods. Therefore, the indicator regeneration rate is set to zero for abiotic resources. However, the decision about relevance of a category should be thoroughly reviewed, because mistakes can lead to an inadequate comparison of resource types. Thus, it is recommended to make this decision based on the judgment of multiple experts. Is the category considered relevant, the approach continues with step 7.

In step 7 the question "Can additional indicators be calculated?" is addressed. This step considers indicators which apply different models (from step 4b), different data sources (from step 5b) as well as categories for which so far no indicator results are determined (from step $2 \mathrm{~b}$ and step $3 \mathrm{~b}$ ). If so far no indicator has been established to quantify a certain category, it is decided whether an indicator of the other methodology can be applied. This is only possible if the underlying data is independent from the resource type (as already determined in step 5b). Thus, there are no specific challenges involved in determining them, besides the additional time that needs to be invested for recalculation. If additional indicators can be calculated the approach continues with step $3 a$ to guarantee that the newly calculated indicators are consistent. If it is not possible to calculate additional indicators, the approach continues with step 8. 
The steps so far are established to compare dimensions, categories and indicators of specific assessment methodologies and combine them to one methodology. Step 8 addresses the question "Can findings of other studies be used to determine results of missing categories?" and thus no longer addresses the considered methodologies, but takes into account results of existing case studies and whether they can be used to determine results of missing dimensions, categories and indicators. Thus, step 8 can only be carried out after the system to be examined was defined. Practitioners should keep in mind that findings from other studies might not consider the same system boundaries, functions, etc. Due to simplifications and assumptions, results might have higher uncertainties, which have to be taken into account. Thus, a thorough analysis is important before using the findings for comparing resources and raw materials. When findings are applicable the results can be included in the overall results and another ending point of the approach is reached ("Results can be included in the overall results"). Otherwise categories (and dimensions), which cannot be assessed are not included in the combined methodology. Here, the fourth ending point is reached ("Exclude dimensions, categories and indicators"). This option however should be avoided and significant effort should be made to include the broadest possible range of categories.

\section{Case study}

In this section the proposed approach is applied to the case study of two methodologies developed by the authors: the integrated methodology to assess resource efficiency (referred to as ESSENZ) for abiotic resources and raw materials (Bach et al. 2016a) and the methodology assessing the availability of terrestrial biotic materials in product systems (referred to as BIRD) (Bach et al. 2017). Both methodologies are shortly introduced in the following. These sections can be skipped by readers familiar with these methods. Further, the implementation of the approach is described in detail for better illustration. The combined methodology is then applied for the case study of three shelves made out of metal, wood and plastic.

\subsection{ESSENZ}

ESSENZ has been developed in cooperation with key players of the European industry (Daimler, Evonik, Knauer, ThyssenKrupp, German Copper Institute (Deutsches Kupferinstitut) and Siemens) to comprehensively measure resource efficiency of products made out of abiotic resources and raw materials (Bach et al. 2016a; Bach et al. 2016b). The aim of the methodology is to enhance the applicability of resource efficiency as well as assess resources in the context of sustainable development. Therefore all three sustainability dimensions (economic, environmental and social) are considered. As the availability of resources and raw materials is a precondition for economic development, the economic dimension is expressed through security of resource supply. ESSENZ takes into account physical as well as socio-economic constraints. The physical availability refers to resources in the earth crusts as well as anthropogenic stocks (e. g. copper cables in dump sites or buildings), whereas the socioeconomic availability is influenced by aspects inhibiting the supply security of resources throughout the supply chain (e. g. trade barriers can prevent the import of necessary materials). To determine the sub dimension physical availability the two indicators abiotic resource depletion (Guinée et al. 1993; Oers et al. 2002) and anthropogenic stock extended abiotic depletion potential (Schneider et al. 2011; Schneider et al. 2015) are applied. The socio-economic availability is addressed by eleven categories and corresponding indicators: Concentration of reserves and production as well as company concentration (Rhoades 1993), demand growth and mining capacity established based on data from (British Geological Survey (BGS) 2014; USGS 2015), feasibility of exploration projects (Cervantes et al. 2013), occurrence as co-product (Angerer et al. 2009), trade barriers (Hanouz et al. 2014), political stability (World Bank Group 2013), primary material use (Graedel 2011) and price fluctuation (Federal Institute for Geosciences and Natural Resources 2014). To determine the characterization factors the distance-to-target approach (Müller-Wenk et al. 1990; Frischknecht et al. 2009) is applied, which sets indicator values in relation to a target value to determine whether the considered materials have a potential supply restriction (which is the case when the indicator value exceeds the target value). Further, environmental impacts related to the extraction and processing of resources and raw materials as well as for the entire product life cycle are assessed applying well established impact assessment methodologies for the categories climate change (Intergovernmental Panel on Climate Change (IPCC) 2007), acidification (Hauschild and Wenzel 1998; Huijbregts 1999), eutrophication (Heijungs et al. 1992), smog (Guinée et al. 2002) and ozone depletion (World Meteorological Organization (WMO) 2010). The social dimension is taken into account by determining aspects considered as not acceptable by society. Thus, the corresponding dimension is referred to as societal acceptance. Within ESSENZ social aspects not accepted by society are identified as child labor, forced labor and materials originating in high conflict zones (Norris et al. 2013) and are expressed in the category compliance with social 
standards. As not only the violation of social but also environmental standards can lead to consumer's boycotting products and companies, the category compliance with environmental standards is added to the dimension as well. Within this category country specific laws and regulations for conservation areas are considered (Yale Center for Environmental Law \& Policy 2014), assuming that a country with better regulations also has fewer violations of environmental standards. Indicators applied to quantify the categories and dimensions considered in ESSENZ are shown in the supplementary material - section 1. Characterization factors for the overall 21 indicators are provided for 40 metals and fossil raw materials by Bach et al. (2016a).

\subsection{BIRD}

BIRD assesses potential restrictions to availability of terrestrial biotic materials and resources for product systems along the supply chain (Bach et al. 2017). Overall the five dimensions physical, socio-economic, abiotic, social and environmental constraints are taken into account. Physical constraints refer to biotic materials extracted from the natural environment (this category is only established for resources) based on Heijungs et al. (1992) and Sas (1997), extraction from the man-made environment as well as the anthroposphere (Bach et al. 2017). The characterization factors of the socio-economic constraints are established based on the distance-to-target approach (Müller-Wenk et al. 1990; Frischknecht et al. 2009), quantifying the following ten categories: concentration of resources and of harvesting as well as company concentration (Rhoades 1993), political instability (World Bank Group 2013), trade barriers (Hanouz et al. 2014), price fluctuations (Barrientos and Soria 2016), storage complexity (Organisation for Economic Cooperation an d Development 2016), occurrence as coproduct as well as recycling and demand growth according to the same calculation principle as applied in ESSENZ (Bach et al. 2016a). Further, phosphorus, land and water as well as natural disasters (United Nations Office for Disaster Risk Reduction 2013; Berger et al. 2014) reduce the occurrence of species used as biotic materials and are considered within the dimension abiotic constraints. The availability of phosphorus and land is only indirectly determined by taking into account the amount of phosphorus and the square meters of land used per functional unit. Limited availability of resources and raw materials can also be caused by social constraints, i.e. compliance with social standards (Norris et al. 2013) and environmental standards (Yale Center for Environmental Law \& Policy 2014) as well as food security (FAO 2016). Further, environmental aspects can reduce the availability of species used as biotic materials. Within BIRD the categories climate change (IPCC 2007), acidification (Hauschild and Wenzel 1998; Huijbregts 1999), eutrophication (Heijungs et al. 1992a), ozone depletion (WMO 2010) and smog (Guinée et al. 2002) are considered. Indicators applied to quantify the categories and dimensions are shown in the supplementary material - section 2.

\subsection{Case study: combining ESSENZ and BIRD}

Following it is described in detail how the eight steps of the proposed approach are applied for the combination of ESSENZ and BIRD. In Figure 3 the number of considered dimensions, categories and indicators included in the combined approach within each step of the proposed approach is shown. Further, the maximal attainable number of dimensions, categories and indicators of the combined approach is highlighted. The combined methodology is shown in Figure 3. Dimensions and categories are visualized with purple frames for ESSENZ and with green frames for BIRD.

The proposed approach starts with step 1a (Are the same dimensions taken into account?): The provided titles of the dimensions in the original publication are considered to determine if the dimensions can be classified are equal. The considered dimensions within ESSENZ and BIRD are referred to differently and are therefore classified as not equal. As the requirements of the first step could not be fulfilled, none of the dimensions can be included in the combined approach within this step. Thus, a comparison of abiotic and biotic resources and raw materials applying ESSENZ and BIRD is not possible without further adapting both methodologies.

Step 1b (Do different dimensions address the same aspects?): Both methodologies consider the dimensions physical and socio-economic constraints/availability as well as environmental impacts/constraints. The dimensions are named slightly differently - constraints/availability - but refer to the same overall challenges and thus can be renamed. The structure of ESSENZ is used as the basis to establish a framework to combine both methodologies. ESSENZ has been chosen as it has been applied in several case studies already and can therefore be seen as more accepted. Further, as the two categories compliance with social and new environmental standards are named the same in both methodologies, the dimension social impacts (in BIRD) is renamed to societal acceptance (as in ESSENZ). BIRD additionally considers the category food security as part of the dimension social impacts, which is therefore also shifted to the dimension societal acceptance. Thus, four of the 
dimensions considered in ESSENZ and BIRD are classified as equal within this step. The dimension abiotic constraints considered in BIRD does not match any dimension addressed in ESSENZ and cannot be included in the combined approach at this point.

Step 2a (Are the same categories considered within equal dimensions): Within the dimension environmental impacts the same categories are taken into account. However, ESSENZ applies these categories to assess environmental impacts of product systems, whereas in BIRD they are considered as potential limitations to availability. Pollution of the environment can change the ecosystem up to the point where cultivated species used as bio-based materials are at risk. Even though a different perspective is applied in both methodologies, eventually the same impacts on the environment are taken into account. Further, within the dimension socioeconomic availability the three categories company concentration, demand growth and trade barriers match. Thus, overall eight categories can be included in the combined approach.

Step 2b (Do different categories address the same aspect?): Several categories within the dimension socioeconomic availability address the same aspect and can be renamed. This includes the categories price variation and price fluctuation (both address rapidly changing prices - renamed to price fluctuations), political instability and stability (renamed to political (in)stability), primary material use and recycling (both address the decreasing pressure on primary resources, when secondary resources are used - renamed to primary material use), concentration of resources and reserves (both consider the concentration of the resource within nature; the term resources is applied for biotic resources, whereas the occurrence of abiotic resources in nature is referred to as reserves - renamed to concentration of resources/reserves), occurrence of co-products and occurrence as co-product (both refer to possible availability constraints due to being a coproduct - renamed to occurrence as co-products) as well as concentration of mine production and concentration of harvesting. The last two categories refer to different activities (mining and harvesting), but both address the concentration of production sites. Thus, a new name is defined (concentration of production), because none of the existing names is adequate to reflect both aspects. After the renaming of the categories, another six categories (additionally to the eight identified in step 2a) can be included in the combined approach.

Step 3a (Are the same indicators applied within equal categories?): The same indicators are applied for the categories of the dimension environmental impacts as well as for the categories demand growth, company concentration, trade barriers, concentration of reserves/resources, primary material use, political (in) stability, occurrence as co-product and concentration of production within the dimension socio-economic availability. Further, indicators applied to determine the categories compliance with social and environmental standards match. Thus, within the combined approach 13 of the overall 14 categories integrated into the combined approach can be quantified with indicators. Different indicators are applied for the category price fluctuations, which therefore cannot be included in the combined approach.

Step 3b (Are the same indicators applied for different categories?): No identical indicators are applied for different categories. Therefore, no additional indicators can be included in the combined approach.

Step 4a (Are the same models applied for each indicator?): For the categories of the dimension environmental impacts the same models are applied. Further, the categories company concentration, demand growth, trade barriers, price fluctuation, political (in)stability, primary material use, concentration of resources/reserves, occurrence as co-products and concentration of production within the dimension socio-economic availability are calculated according to the same principle. Thus, none of the 13 indicators so far included in the combined approach have to be excluded.

Step $4 \mathrm{~b}$ (Can other models be adapted to recalculate the indicators?): It is possible to adapt the models of BIRD for the categories compliance with social and environmental standards to the model applied in ESSENZ. Both categories are recalculated (in step 7) and then reevaluated according to the requirements stated in steps 3a to $5 a$ to guarantee consistency. Thus, two more categories and indicators can be included in the combined approach (see step 7).

Step 5a (Are the same data applied for each indicator?): Only for the dimension environmental impacts the same data are applied. For the indicators of the dimension socioeconomic availability some of the used data are equal (underlying indicators, e.g. Worldwide Governance Indicators

(Kaufmann et al. 2011; World Bank Group 2013)) and some are different (source of the global production shares). Thus, data sources for these indicators have to be further investigated in step 5b. 
Step $5 b$ (Are the data specific for resources and raw materials): For the calculation of the indicator results for the dimension socio-economic availability, data sources identified as different in step 5 a are resource and raw material specific. Production shares of abiotic materials are taken from USGS (2015) and BGS (2014), whereas for biotic raw materials various data sources addressing biotic materials e.g. FAO (2015) are used. Thus, no adjustments of the underlying data are necessary.

The ending point "Dimension, categories and indicators are included in the combined methodology" is reached, leading to following dimensions and categories to be included in the combined methodology:

- The dimensions environmental impacts, societal acceptance, physical availability and socio-economic availability

- All categories and indicators of the dimension environmental impacts

- The categories (and corresponding indicators) demand growth, company concertation, price fluctuation, trade barriers, concentration of production, occurrence as co-product, political (in) stability, primary material use and concentration of reserves/resources of the dimension socio-economic availability

Next categories and indicators, which could not be included in the combined methodology, are analyzed further. Starting with step 6 (Are the missing categories relevant for the evaluated resource or raw material?) the relevance of categories is analyzed. Both methodologies address categories which are not covered by the other methodology. Categories addressed in ESSENZ but not in BIRD are mining capacity and feasibility of exploration projects. Both can be set to zero and thus reach another ending point of the approach ("Set indicator value of this category to zero"):

- Mining capacity: As biotic resources and raw materials can be replenished, their availability is not limited by the extraction and reserve rate used to determine mining capacity.

- Feasibility of exploration projects: Cultivation of agricultural and forestry products is easier to establish than mining activities.

Categories addressed by BIRD but not by ESSENZ are replenishment rate of the dimension physical availability, storage complexity of the dimension socio-economic availability, all categories of the dimension abiotic constraints as well as the category food security of the dimension societal acceptance (originally social constraints). Following categories are not relevant for the assessment of abiotic resources and can be set to zero:

- Replenishment rate: Abiotic resources are formed over very long geological periods and are therefore not renewable.

- Food security: Abiotic resources cannot be used as food and are therefore not in direct competition of use. Indirect influences such as land use or impacts on the environment are considered in the other dimension.

- Phosphorus availability: Phosphorus itself is an abiotic resource, but other abiotic resources and raw materials are not influenced by its availability.

Thus, to the already 16 categories and 15 indicators considered in the combined approach, five additional categories and indicators can be included.

Step 7 (Can additional indicators be calculated?): The indicators of the categories compliance with social and environmental standards can be recalculated as already mention in step $4 b$. For the category storage complexity as well as the categories natural disasters, land and water availability indicators can be calculated for abiotic resources according to BIRD. The newly calculated indicators have to be evaluated going through the individual stages of the approach (starting with step 3a) before they can be included in the combined methodology. This procedure is not described here because the same steps as explained before are applied. All newly calculated indicators can be included in the combined methodology. Thus, one more dimension, four more categories and five more indicators can be included in the combined approach. 


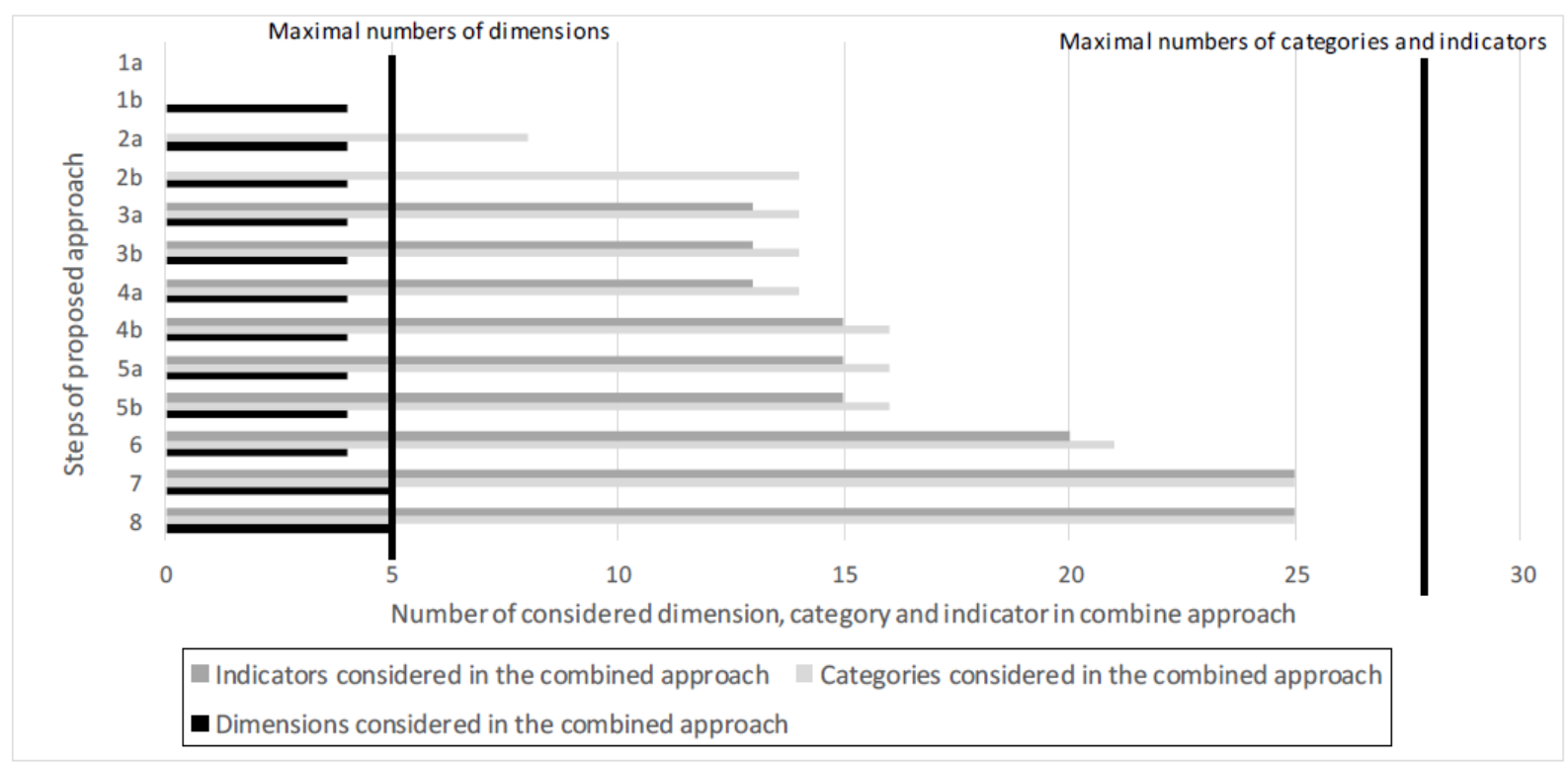

Figure 2: Overview of considered dimensions, categories and indicators included in the combined methodology within each step of the proposed approach; including maximal numbers of dimensions, categories and indicators possible for the combined approach

Step 8 (Can findings of other studies be used to determine results of missing categories?) is the last step applied: here not the methodologies as such, but the case study for which the combined methodology shall be applied for, is the basis for completing the step. The case study chosen here (comparison of shelves made out of steel, polypropylene (PP) and oak wood) is introduced later, but results are addressed here for the sake of completeness. At this point, only for the categories physical and anthropogenic availability different indicators are applied, which cannot be compared. Thus, research is carried out with regard to existing studies addressing the physical and anthropogenic availability of the materials steel, PP and oak wood. Such studies do not exist. Thus, another ending point is reached ("Exclude dimensions, categories and indicators"). Thus, no additional categories and indicators can be included in the combined approach.

By applying the proposed approach to join ESSENZ and BIRD the combined methodology consists of overall five dimensions composed of 25 categories and indicators. Only the two categories resource depletion and anthropogenic availability with their corresponding indicators cannot be included due to different and not transferrable indicator models.

As ESSENZ considers four dimensions with overall 21 categories and indicators and BIRD takes into account five dimensions with overall 24 categories and indicators, the maximal number of dimensions, categories and indicators to be considered in the combined approach adds up to five dimensions and 27 categories and indicators. 
Dimension
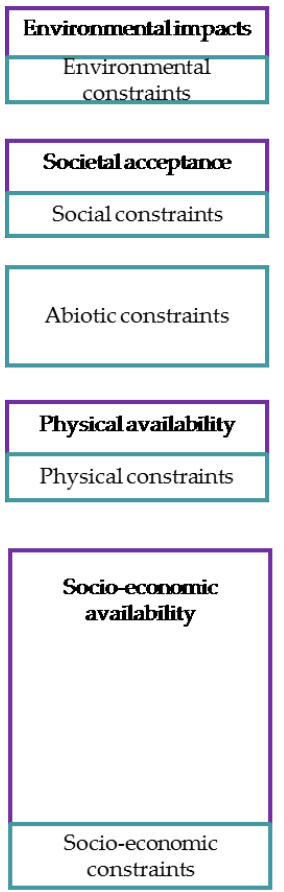
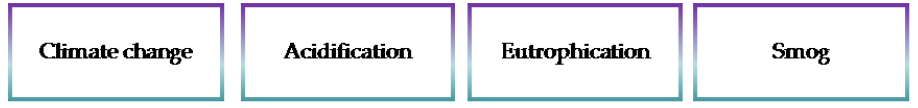

Ozonedepletion
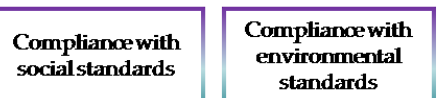

Food security
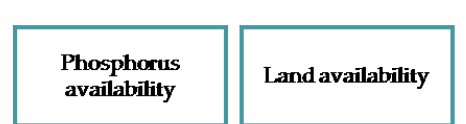

Water availability

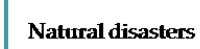

availability
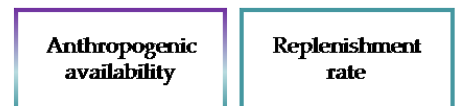

$$
\begin{gathered}
\text { depletion } \\
\text { (biotic\& abiotic) }
\end{gathered}
$$
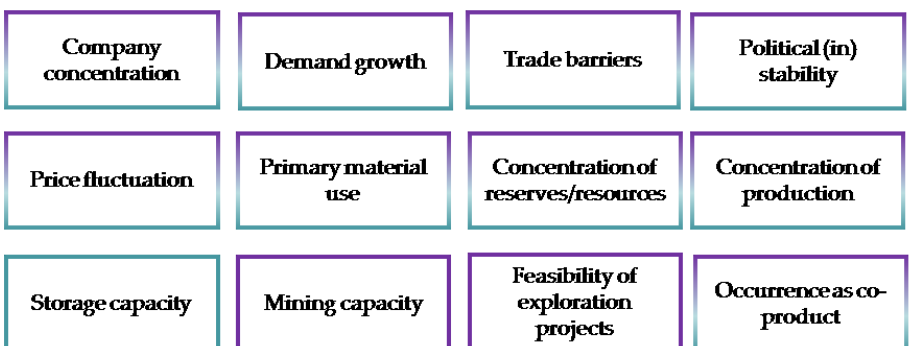

Occurrenceas coproduct

Figure 3: Combined methodology applying the proposed approach: dimensions and categories are highlighted by purple frames when considered in ESSENZ and by green frames for BIRD

Figure 4: Proportional comparison of results of case study - shelves made out of polypropylene (PP), steel and oak

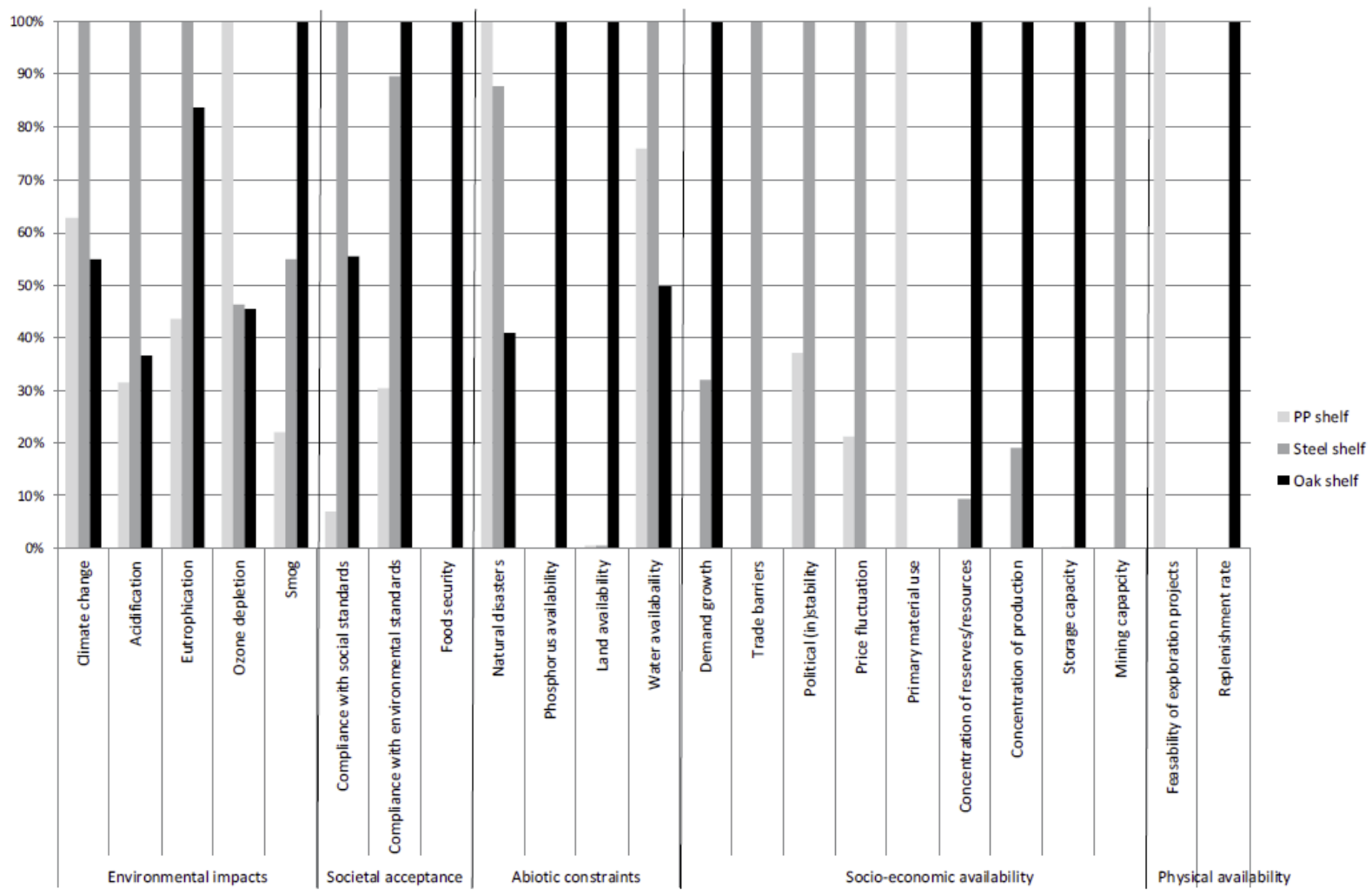




\subsection{Application of combined approach}

Next, the combined methodology is applied for the case study of three shelves. Shelves with the same function (storage of undefined items with a carrying capacity of $30 \mathrm{~kg}$ ) made out of the three different materials steel (10.7 $\mathrm{kg})$, PP $(5.8 \mathrm{~kg}$ ) and oak $(38 \mathrm{~kg})$ are considered. The masses of the shelves are assumed based on data provided by Inter IKEA Systems B.V. (2017). For all three shelves only the production phase is taken into account (excluding use and end of life phase), which were modeled in GaBi (Thinkstep 2016), using GaBi and ecoinvent data (Ecoinvent 2016). Further, several additional simplifications were made with regard to the system boundaries as the purpose of this case study is to demonstrate the applicability of the combined approach only and not to provide reliable results.

\begin{tabular}{|l|l|l|l|l|}
\hline Dimension & Category & PP shelf & Steel shelf & Oak shelf \\
\hline \multirow{5}{*}{} & Resource depletion - metals & n.t. & $5.61 \mathrm{E}-07$ & n.t. \\
\cline { 2 - 5 } & Resource depletion - biotic & n.t. & n.t. & $1.03 \mathrm{E}-12$ \\
\cline { 2 - 5 } & resource depletion - fossils & 245.51 & n.t. & n.t. \\
\cline { 2 - 5 } & Anthropogenic availability & n.t. & $8.51 \mathrm{E}-04$ & n.t. \\
\hline n.t. - indicators are not transferable & \multicolumn{2}{|l}{} \\
\hline
\end{tabular}

Table 1: Results of the dimension physical availability of the case study - shelves made out of poly-

The combined methodology consists of five dimensions with overall 25 categories and indicators. A direct comparison of the results can only be carried out individually for every category. As the categories have different units comparison across categories is not possible (results for each category are displayed in the supplementary materials - section 3). Thus, a proportional assessment is used to compare the results of all categories and dimensions for the three shelves (see Figure 4). The proportional comparison is determined by setting the highest result study within each category to $100 \%$ and determining the percentage share of the other results of the categories.

As mentioned before the purpose of the case is to demonstrate the applicability of the combined approach. Thus, when reflecting upon the results it should be kept in mind that several assumptions were made. Further, as no weighting factors are applied, neither the importance of the individual categories can be assessed, nor an single score result can be determined. An imbalance of the results also occurs as more categories for the dimension socio-economic availability are taken into account than for other dimensions. Further, the categories resource depletion and anthropogenic availability could not be displayed in Figure 4, because the indicators of the categories are not transferable (as shown in the results derived by applying the approach).

However, as especially these two categories are of importance for plastic and its fossil raw materials, the overall comparison of the tree shelves is somewhat limited. Results of the categories resource depletion as well as anthropogenic availability for all three shelves are displayed in Table 1 for the sake of completeness. A comparison of the tree shelves without the combined methodology is not possible, because none of the dimensions, categories and indicators match. Only after applying the proposed approach the combined methodology is established considering all five dimensions and 25 out of 27 categories and indicators. The combined methodology can then be applied for the comparison of shelves. Thus, the results show more information gained from the case study compared to the isolated application of the methods.

\section{Discussion}

The aim of the proposed approach is to provide guidance on how different methodologies can be combined to complement each other to accomplish an adequate evaluation of different resource types. Related challenges are addressed in the following.

The proposed approach is developed for the combination of methodologies assessing resource use of different resource types. Maturity of indicators has to be determined when two methodologies considering the same resource type are combined. The proposed approach is not developed to establish such an assessment of indicator maturity. However, several elements, e. g. the analysis of the indicator model and underlying data, could be also applied for the assessment of indicator maturity. Further ideas on how such an assessment could 
be carried out is shown in Bach and Finkbeiner (2016). However, to some extent determining indicator maturity is also necessary to apply the proposed approach, especially in step 7, where indicators have to be recalculated. To determine maturity of indicators practitioners can use existing indicator evaluations, e. g. Joint Research Centre (2011), Rack et al. (2013) and Lehmann et al. (2015).

To apply the provided approach adequately practitioners should have proper understanding of the methodologies considered. Particular attention should be devoted in general to choices for the combined methodology (e. g. relying on solid information about categories and indicators in order to decide whether they can be set as equal).

This can be challenging especially when the methodology is not documented sufficiently. In fact, many methodologies provide accurate information with regard to the indicator itself but the underlying data cannot be accessed (e. g. the EUTREND model used for calculating characterization factors for the category acidification in ReCiPe (Huijbregts et al. 2017)), and therefore not all details are available.

Further, lack of understanding can lead to wrong decisions in the individual steps of the approach. This is especially relevant for step 6 and step 8. In step 6 results of a category are set to zero, when the category is classified as not relevant for the considered resource type. If the practitioner is not familiar with all aspects of a specific resource type, faulty evaluations in this step will lead to an inadequate combined methodology. In step 8 findings of other studies are used to determine category results. However, applying these results correctly can be challenging, because parameters of the studies have to be thoroughly reviewed and interpreted correctly.

To guarantee adequate comparability, categories have to be excluded, when quantification is not possible. However, exclusion of categories always means that relevant aspects are not taken into account. As shown in the case study the exclusion of categories can be minimized when the other steps are thoroughly carried out.

The resources phosphorus, water and land can be evaluated as own resources, but are also considered within assessment methodologies for the evaluation of abiotic and biotic resources. Within the methodologies of the case study land as well as water availability are considered applying one indicator. In reality both resource types are more complex and can be assessed applying several indicators as shown for example in the publication by Sonderegger et al. (2015). The same applies to phosphorus, which is considered as one aspect for biotic resources, but is a resource itself with its own availability constraints and environmental implications.

Combining multi-indicator methodologies supports a more comprehensive assessment of resource use. However, the practitioner should be aware that this does not mean that all aspects relevant for the resource type are taken into account. Especially when only one indicator per methodology is established the practitioner has to be aware that several aspects relevant for the considered resource types are not addressed. However, depending on the goal of the case studies addressing only few indicators might be feasible.

\section{Conclusion}

The proposed approach provides guidance on how different methodologies can be combined to complement each other to accomplish the assessment of different resource types. Therefore, a user-friendly flow chart for easy application is established leading the user through the comparison and combination of the methodologies in eight steps. Dimensions, categories, indicators, underlying models and data can be included in the combined approach when they fulfill the requirements of the individual steps.

A case study of two methodologies developed by the authors demonstrates the applicability of the approach. The individual methodologies cannot be used for the consistent assessment of different resources types, because none of the dimensions, categories and indicators of ESSENZ and BIRD match. After the proposed approach has been applied all five dimensions and 25 of the 27 considered categories and indicators can be integrated into the combined approach. The combined methodology can be applied to determine implications of resource use of different resource types. Further, the combined methodology is tested for a case study of three shelves (made out of oak, PP and steel). The results show an increased level of knowledge gained from the case study compared to the isolated application of the methods. Thus, the approach presented in this paper allows for a more comprehensive and meaningful assessment of resource use in life cycle assessment. 


\section{Acknowledgment}

Part of the work presented here was prepared in the context of the DFG project ResMob (Assessment of abiotic and biotic resources within the mobility sector - development of assessment criteria, methods and concepts) (project number: Fl 1622/6-1). 


\section{References}

Achzet B, Helbig C (2013) How to evaluate raw material supply risks - an overview. Resour Policy 38:435-447. doi: 10.1016/j.resourpol.2013.06.003

Alvarenga RAF, Dewulf J, Van Langenhove H (2013) A new natural resource balance indicator for terrestrial biomass production systems. Ecol Indic 32:140-146. doi: 10.1016/j.ecolind.2013.03.029

Angerer G, Erdmann L, Marscheider-Weidemann F, et al (2009) Rohstoffe für Zukunftstechnologien Rohstoffe für Zukunftstechnologien. https://www.deutscherohstoffagentur.de/DERA/DE/Downloads/Studie_Zukunftstechnologien2016.pdf?_blob=publicationFile\&v=3. Accessed Feb 2017

Bach V, Berger M, Finogenova N, Finkbeiner M (2017) Assessing the Availability of Terrestrial Biotic Materials in Product Systems (BIRD). Sustainability 9:137. doi: 10.3390/su9010137

Bach V, Berger M, Henßler M, et al (2016a) Integrated method to assess resource efficiency - ESSENZ. J Clean Prod. doi: 10.1016/j.jclepro.2016.07.077

Bach V, Berger M, Henßler M, et al (2016b) Messung von Ressourceneffizienz mit der ESSENZ-Methode - Integrierte Methode zur ganzheitlichen Bewertung. Springer/Spektrum. Berlin/Heidelberg. ISBN 978-3-662-49263-5

Bach V, Finkbeiner M (2016) Approach to qualify decision support maturity of new versus established impact assessment methods demonstrated for the categories acidification and eutrophication. Int J Life Cycle Assess. doi: 10.1007/s11367-016-1164-z

Bare J (2002) Developing a Consistent Decision-Making Framework by Using the U.S. EPA's TRACI. https://cluin.org/conf/tio/lcia/AICHE2002paper.pdf. Accessed Feb 2017

Barrientos M, Soria C (2016) IndexMundi. http://www.indexmundi.com/about.html. Accessed Feb 2016

Beck T, Bos U, Wittstock B, et al (2010) LANCA $^{\circledR}$ Land Use Indicator Value Calculation in Life Cycle Assessment - Method Report. http://www.lbp-gabi.de/files/lanca_website.pdf. Accessed Feb 2017

Berger M, Sonderegger T (2017) Harmonizing the assessment of resource use in LCA - First results of the task force on natural resources of the UNEP-SETAC global guidance on environmental life cycle impact assessment indicators project. In: SETAC Europe 27th Annual Meeting, May 8-11, Brussels, Belgium.

Berger M, van der Ent R, Eisner S, et al (2014) Water accounting and vulnerability evaluation (WAVE): considering atmospheric evaporation recycling and the risk of freshwater depletion in water footprinting. Environ Sci Technol 48:4521-8. doi: 10.1021/es404994t

British Geological Survey (2014) World Mineral Production. https://www.bgs.ac.uk/mineralsuk/statistics/worldSta tistics.html. Accessed Feb 2015

Cervantes M, McMahon F, Wilson A (2013) Survey of Mining Companies: 2012/2013. www.fraserinstitute.org/sites/default/files/miningsurvey-2012-2013.pdf. Accessed Feb 2016

Crenna E, Sala S (2017) Making biotic resources count in the LCIA framework. In: SETAC Europe 27th Annual Meeting, May 8-11, Brussels, Belgium.

Dewulf J, Blengini GA, Pennington D, et al (2016) Criticality on the international scene: Quo vadis? Resour Policy 50:169-176. doi: 10.1016/j.resourpol.2016.09.008

Ecoinvent (2016) Ecoinvent database. www.ecoinvent.org

European Commission (2005) Thematic Strategy on the sustainable use of natural resources. http://ec.europa.eu/environment/archives/natres/inde x.htm. Acessed Dez 2015

European Commission (2014) Report on Critical raw materials for the EU.

http://ec.europa.eu/DocsRoom/documents/10010/attac hments/1/translations/en/renditions/pdf. Accessed Feb 2016

Federal Institute for Geosciences and Natural Resources (2014) Volatilitätsmonitor. http://www.deutscherohstoffagentur.de/DERA/DE/Rohstoffinformationen/ Rohstoffpreise/Volatilit\%C3\%A4tsmonitor/volatilit\%C3\%A4tsmonitor_node.html. Accessed Mar 2015

Finkbeiner M, Ackermann R, Bach V, et al (2014) Challenges in Life Cycle Assessment: An Overview of Current Gaps and Research Needs. In: Background and Future Prospects in Life cycle Assessment. Springer Berlin / Heidelberg, pp 207-258

Finnveden G, Arushanyan Y, Brandão M (2016) Exergy as a Measure of Resource Use in Life Cycle Assessment and Other Sustainability Assessment Tools. Resources 5:23. doi: 10.3390/resources5030023

Food and Agriculture Organization of the United Nations (2015) Forestry Production and Trade. http://www.fao.org/faostat/en/\#data/FO. Accessed Mar 2016 
Food and Agriculture Organization of the United Nations (2016) Food security indicators. http://www.fao.org/economic/ess/ess-fs/essfadata/en/\#.V2jUO1SLSUn. Accessed Feb 2016

Frischknecht R, Steiner R, Jungbluth N, Büsser Knöpfel S (2009) The Ecological Scarcity Method: Eco-Factors 2006 - A method for impact assessment in LCA. Environmental studies no. 0906. Federal Office for the Environment, Bern

Giddings B, Hopwood B, O'Brien G (2002) Environment, economy and society: fitting them together into sustainable development. Sustain Dev 10:187-196. doi: 10.1002/sd.199

Graedel TE (2011) UNEP Recycling rates of metals - A Status Report, a Report of the Working Group on the Global Metal Flows to the international Resource Panel.

Graedel TE, Barr R, Chandler C, et al (2012) Methodology of metal criticality determination. Environ Sci Technol 46:1063-1070.

Guinée JB, Gorrée M, Heijungs R, et al (2002) Handbook on life cycle assessment. Operational guide to the ISO standards. I: LCA in perspective. Ila: Guide. IIb: Operational annex. III: Scientific background.

Guinée JB, Heijungs R, Haes HAU de, Huppes G (1993) Quantitative life cycle assessment of products - 2. Classification, valuation and improvement analysis.

Hanouz MD, Geiger T, Doherty S (2014) The Global Enabling Trade Report 2014. https://www.weforum.org/reports/global-enablingtrade-report-2014. Accessed Feb 2016

Hauschild MZ, Wenzel H (1998) Environmental Assessment of Products - Volume 2: Scientific Background. ISBN 978-0-412-80810-4

Heijungs R, Guinée JB, Huppes G, et al (1992a) Environmental life cycle assessment of products: guide and backgrounds (Part 1). https://openaccess.leidenuniv.nl/handle/1887/8061. Accessed Mar 2016

Heijungs R, Guinée JB, Huppes G, et al (1992b) Environmental life cycle assessment of products - guide and backgrounds (Part 2). https://openaccess.leidenuniv.nl/handle/1887/8062. Accessed Mar 2016

Hein L, Leemans R (2012) The Impact of First-Generation Biofuels on the Depletion of the Global Phosphorus Reserve. Ambio 41:341-349. doi: $10.1007 / \mathrm{s} 13280-012-0253-x$

Huijbregts M a. J (1999) Life-cycle impact assessment of acidifying and eutrophying air pollutants. http://media.leidenuniv.nl/legacy/Lifecycle\%20impact\%20assessment.pdf. Accessed Mar 2016

Huijbregts MAJ, Steinmann ZJN, Elshout PMF, et al (2017) ReCiPe2016: a harmonised life cycle impact assessment method at midpoint and endpoint level. Int J Life Cycle Assess 22:138-147. doi: 10.1007/s11367-016-1246-y

Inter IKEA Systems B.V. (2017) No Title. In: Billy. http://www.ikea.com/de/de/catalog/products/00263850/. Accessed May 2017

Intergovernmental Panel on Climate Change (2007) IPCC Climate Change Fourth Assessment Report: Climate Change. In: IPCC Clim. Chang Fourth Assess. Rep. Clim. Chang. http://www.ipcc.ch/ipccreports/assessmentsreports.htm. Accessed Jun 2015

Joint Research Centre (2011) International Reference Life Cycle Data System (ILCD) Handbook - Recommendations for Life Cycle Impact Assessment in the European context. http://eplca.jrc.ec.europa.eu/uploads/ILCDRecommendation-of-methods-for-LCIA-def.pdf. Accessed Dez 2015

Kaufmann D, Kraay A, Mastruzzi M (2011) The Worldwide Governance Indicators: Methodology and Analytical Issues. Hague J Rule Law 3:220-246. doi: $10.1017 / S 1876404511200046$

KlingImair M, Sala S, Brandão M (2014) Assessing resource depletion in LCA: A review of methods and methodological issues. Int J Life Cycle Assess 19:580-592. doi: 10.1007/s11367-013-0650-9

Koellner T, Baan L, Beck T, et al (2013) UNEP-SETAC guideline on global land use impact assessment on biodiversity and ecosystem services in LCA. Int J Life Cycle Assess 18:1188-1202. doi: 10.1007/s11367-013-0579-2

Lehmann A, Bach V, Finkbeiner M. (2015) Product Environmental Footprint in policy and market decisions - applicability and impact assessment. Integr Environ Assess Manag 11:417-424.

March MD, Toma L, Stott AW, Roberts DJ (2016) Modelling phosphorus efficiency within diverse dairy farming systems - pollutant and nonrenewable resource? Ecol Indic 69:667-676. doi: 10.1016/j.ecolind.2016.05.022

Mousavi-Avval SH, Rafiee S, Sharifi M, et al (2017) Use of LCA indicators to assess Iranian rapeseed production systems with different residue management practices. Ecol Indic 80:31-39. doi: 10.1016/j.ecolind.2017.04.045

Müller-Wenk R, Ahbe S, A. B (1990) Methodik für Ökobilanzen auf der Basis ökologischer Optimierung. in: Schriftreihe Umwelt Nr. 133. hrsg. vom Bundesamt für Umwelt, Wald und Landschaft (BUWAL). Bern, 1990.

Norris CB, Norris G, Aulisio D (2013) Social Hotspots Database. http://socialhotspot.org/. 
Núñez M, Bouchard CR, Bulle C, et al (2016) Critical analysis of life cycle impact assessment methods addressing consequences of freshwater use on ecosystems and recommendations for future method development. Int J Life Cycle Assess 21:1799-1815. doi: 10.1007/s11367-016-1127-4

Oakdene Hollins (2014) Study on Critical Raw Materials at EU level Final Report. 148-151. File reference number: EC-11 315 -Final Report Issue 3.docx

Oers L van, Konig A de, Guinée JB, Huppes G (2002) Abiotic resource depletion in LCA Abiotic resource depletion in LCA Improving characterisation factors for abiotic ressource depletion as recommended in the new Dutch LCA Handbook.

Organisation for Economic Cooperation and Development (2016) Economic resilience. http://www.oecd.org/economy/growth/economicresilience.htm. Accessed Feb 2016

Pfister S, Boulay A-M, Berger M, et al (2017) Understanding the LCA and ISO water footprint: A response to Hoekstra (2016) "A critique on the water-scarcity weighted water footprint in LCA." Ecol Indic 72:352-359. doi: 10.1016/j.ecolind.2016.07.051

Pfister S, Koehler A, Hellweg S (2009) Assessing the Environmental Impacts of Freshwater Consumption in LCA. Environ Sci Techno 43:4098-4104. doi: 10.1021/es802423e

Rack M, Valdivia S, Sonnemann G (2013) Life Cycle Impact Assessment-where we are, trends, and next steps: a late report from a UNEP/SETAC Life Cycle Initiative workshop and a few updates from recent developments. Int J Life Cycle Assess 18:1413-1420. doi: 10.1007/s11367-013-0569-1

Rhoades SA (1993) The Herfindahl-Hirschman index. Federal Reserve Bulletin. Volume 79, Issue 3, Pages 188-189

Ritthoff M, Rohn H, Liedtke C (2002) Calculating MIPS - Resource productivity of products and services. Wuppertal: Wuppertal Institute for Climate, Environment and Energy.

Rulli MC, Bellomi D, Cazzoli A, et al (2016) The water-landfood nexus of first-generation biofuels. Sci Rep 6:22521. doi: 10.1038/srep22521

Sas H (1997) Extraction of biotic resources: development of a methodology for incorporation in LCAs, with case studies on timber and fish. Ministerie van Volkshuisvesting, Ruimtelijke Ordening en Milieubeheer, Centrale Directie Voorlichting en Externe Betrekkingen, 1997

Schneider L, Bach V, Finkbeiner M (2016) LCA Perspectives for Resource Efficiency Assessment. in: LCA Compendium - The Complete World of Life Cycle Assessment -Special Types of Life Cycle Assessment. Springer: Dodrecht, The Netherlands. pp 179-218. ISBN 97894-017-7608-0

Schneider L, Berger M, Finkbeiner M (2011) The anthropogenic stock extended abiotic depletion potential (AADP) as a new parameterisation to model the depletion of abiotic resources. Int J Life Cycle Assess 16:929-936. doi: 10.1007/s11367-011-0313-

Schneider L, Berger M, Finkbeiner M (2015) Abiotic resource depletion in LCA-background and update of the anthropogenic stock extended abiotic depletion potential (AADP) model. Int J Life Cycle Assess. doi: 10.1007/s11367-015-0864-0

Sonderegger T, Dewulf J, Fantke P, et al (2017) Towards harmonizing natural resources as an area of protection in life cycle impact assessment. Int J Life Cycle Assess. doi: 10.1007/s11367-017-1297-8

Sonderegger T, Pfister S, Hellweg S (2015) Criticality of Water: Aligning Water and Mineral Resources Assessment. Environ Sci Technol 49:12315-12323. doi: 10.1021/acs.est.5b02982

Sonnemann G, Gemechu ED, Adibi N, et al (2015) From a critical review to a conceptual framework for integrating the criticality of resources into Life Cycle Sustainability Assessment. J Clean Prod 94:20-34. doi: 10.1016/j.jclepro.2015.01.082

Thinkstep (2016) GaBi Product Sustainability Software. www.gabi-software.com

United Nations Office for Disaster Risk Reduction (2013)

Global Risk Data Platform. In: Flood events 1999-2007, Droughts events 1980-2001.

http://preview.grid.unep.ch/index.php?preview=data \&events=floods\&evcat=1\&lang=eng. Accessed Feb 2016

United States Geological Survey (2015) Commodity Statistics and Information. http://minerals.usgs.gov/minerals/pubs/commodity/. Accessed May 2004

Valero A, Carpintero Ó, Valero A, Calvo G (2014) How to account for mineral depletion. The exergy and economic mineral balance of Spain as a case study. Ecol Indic 46:548-559. doi: 10.1016/j.ecolind.2014.07.021

van Oers L, Guinée J (2016) The Abiotic Depletion Potential: Background, Updates, and Future. Resources 5:16. doi: $10.3390 /$ resources5010016

World Bank Group (2013) The Worldwide Governance Indicators. http://info.worldbank.org/governance/wgi/index.aspx\#home. Accessed Mar 2015 
World Meteorological Organization (2010) Scientific Assessment of Ozone Depletion : 2010 Global Ozone Research and Monitoring Project-Report No. 52

Yale Center for Environmental Law \& Policy (2014) Environmental Performance Index. In: 2014 Environ. Perform. Index. http://epi.yale.edu/. Accessed Mar 2015

Zabalza Bribián I, Valero Capilla A, Aranda Usón A (2011) Life cycle assessment of building materials: Comparative analysis of energy and environmental impacts and evaluation of the eco-efficiency improvement potential. Build Environ 46:1133-1140. doi: 10.1016/j.buildenv.2010.12.002 


\section{Supplementary Materials}

Comprehensive approach for evaluating different resource types- Case study of abiotic and biotic resource use assessment methodologies

Vanessa Bach ${ }^{1}$, Markus Berger ${ }^{1}$, Silvia Forin ${ }^{1}$ and Matthias Finkbeiner ${ }^{1}$

${ }^{1}$ Technische Universität Berlin, Chair of Sustainable Engineering, Straße des 17. Juni 135, 10623 Berlin, Germany

* Corresponding author: vanessa.bach@tu-berlin.de

\section{Table of contents}

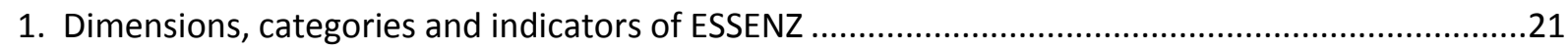

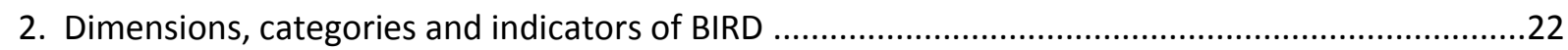

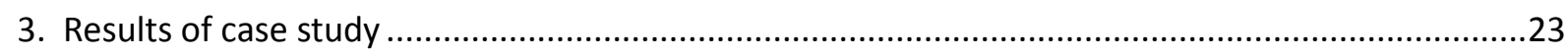

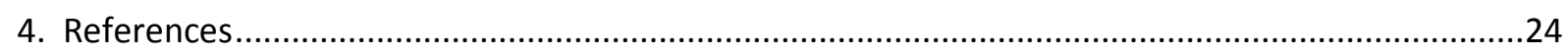




\section{Dimensions, categories and indicators of ESSENZ}

The dimensions, categories and indicators applied in the integrated method to assess resource efficiency (referred to as ESSENZ) (Bach et al. 2016) are shown in Table S.1.

Table S.1: Overview of dimensions, categories and indicators considered in ESSENZ

\begin{tabular}{|c|c|c|}
\hline Dimension & Category & Category indicator \\
\hline \multirow[t]{12}{*}{$\begin{array}{l}\text { Physical } \\
\text { availability }\end{array}$} & Abiotic resource depletion & $\begin{array}{l}\text { Abiotic resource depletion indicator (Guinée et al. } \\
\text { 1993; Oers et al. 2002) or anthropogenic stock } \\
\text { extended abiotic depletion potential (Schneider et al. } \\
\text { 2011; Schneider et al. 2015) }\end{array}$ \\
\hline & Company concentration & \\
\hline & Concentration of reserves & \\
\hline & Concentration of production & \\
\hline & Mining capacity & $\begin{array}{l}\text { Reserve-to-annual-production ratio (based on data } \\
\text { from (United States Geological } \\
\text { Survey 2015) and BGS (British Geological Survey 2014)) }\end{array}$ \\
\hline & Feasibility of exploration projects & Policy Potential Index (Cervantes et al. 2013) \\
\hline & Occurrence as coproduct & $\begin{array}{l}\text { Percentage of production as companion metal } \\
\text { (Angerer et al. 2009) }\end{array}$ \\
\hline & Trade barriers & Enabling Trade Index (Hanouz et al. 2014) \\
\hline & Political stability & $\begin{array}{l}\text { World Governance Indicators (World Bank } \\
\text { Group 2013) }\end{array}$ \\
\hline & Demand growth & $\begin{array}{l}\text { Percentage of annual growth based on past } \\
\text { developments (based on data from BGS (British } \\
\text { Geological Survey 2014)) }\end{array}$ \\
\hline & Primary material use & $\begin{array}{l}\text { Percentage of new material content (Graedel } \\
\text { 2011) }\end{array}$ \\
\hline & Price fluctuation & $\begin{array}{l}\text { Volatility (Federal Institute for Geosciences and } \\
\text { Natural Resources 2014) }\end{array}$ \\
\hline & Compliance with social standards & $\begin{array}{l}\text { Child labor, forces labor and high conflict zones (based } \\
\text { on Norris et al. 2013) }\end{array}$ \\
\hline & $\begin{array}{l}\text { Compliance with environmental } \\
\text { standards }\end{array}$ & $\begin{array}{l}\text { Sub indicators of Environmental Performance Index } \\
\text { (Yale Center for Environmental Law \& Policy 2014) }\end{array}$ \\
\hline & Climate change & $\begin{array}{l}\text { Increasing radiative forcing } \\
\text { (Intergovernmental Panel on Climate Change 2007) }\end{array}$ \\
\hline & Acidification & $\begin{array}{l}\text { Proton release (Hauschild and Wenzel 1998; } \\
\text { Huijbregts 1999) }\end{array}$ \\
\hline & Eutrophication & $\begin{array}{l}\text { Increased supply of nutrients (Heijungs et al. } \\
\text { 1992) }\end{array}$ \\
\hline
\end{tabular}




\begin{tabular}{|l|l|}
\hline Ozone layer depletion & $\begin{array}{l}\text { Release of chloride and bromide ions (World } \\
\text { Meteorological Organization 2010) }\end{array}$ \\
\hline Smog & $\begin{array}{l}\text { Tropospheric ozone formation (Guinée et al. } \\
\text { 2002) }\end{array}$ \\
\hline
\end{tabular}

\section{Dimensions, categories and indicators of BIRD}

The dimensions, categories and indicators applied in the method assessing the availability of terrestrial biotic materials in product systems (referred to as BIRD) (Bach et al. 2017) are shown in Table S.2.

Table S.2: Overview of dimensions, categories and indicators considered in BIRD

\begin{tabular}{|c|c|c|}
\hline \multirow[t]{4}{*}{ Dimension } & Category & Category indicator \\
\hline & Biotic resource depletion & $\begin{array}{l}\text { Biotic resource depletion (Heijungs et al. 1992; } \\
\text { Sas 1997) }\end{array}$ \\
\hline & Replenishment rate & Approach developed by (Bach et al. 2017) \\
\hline & Anthropogenic availability & Approach developed by (Bach et al. 2017) \\
\hline & Company concentration & \\
\hline & Concentration of reserves & \\
\hline & Concentration of harvesting & \\
\hline & Political instability & $\begin{array}{l}\text { World Governance Indicators (World Bank } \\
\text { Group 2013) }\end{array}$ \\
\hline & Trade barriers & Enabling Trade Index (Hanouz et al. 2014) \\
\hline & Price fluctuations & $\begin{array}{l}\text { Commodity price index by (Barrientos and } \\
\text { Soria 2016) }\end{array}$ \\
\hline & Storage complexity & $\begin{array}{l}\text { Economic Vulnerability Indicator } \\
\text { (Organisation for Economic Cooperation and } \\
\text { Development 2016) }\end{array}$ \\
\hline & Primary material use & \\
\hline & Occurrence as coproduct & \\
\hline & Demand growth & \\
\hline & Phosphorus availability & Amount of phosphorus used \\
\hline & Land availability & Square meters of land used \\
\hline & Water availability & Water Depletion Index (Berger et al. 2014) \\
\hline & Natural disasters & $\begin{array}{l}\text { Droughts and floods (United Nations Office for Disaster } \\
\text { Risk Reduction 2013) }\end{array}$ \\
\hline & $\begin{array}{l}\text { Compliance with social } \\
\text { standards }\end{array}$ & $\begin{array}{l}\text { Child labor, forces labor and high conflict zones based } \\
\text { on (Norris et al. 2013) }\end{array}$ \\
\hline
\end{tabular}




\begin{tabular}{|c|c|}
\hline $\begin{array}{l}\text { Compliance with environmental } \\
\text { standards }\end{array}$ & $\begin{array}{l}\text { Sub indicators of Environmental Performance } \\
\text { Index (Yale Center for Environmental Law \& Policy } \\
\text { 2014) }\end{array}$ \\
\hline Food security & $\begin{array}{l}\text { Food security index (Food and Agriculture } \\
\text { Organization of the United Nations 2016) }\end{array}$ \\
\hline Climate change & $\begin{array}{l}\text { Increasing radiative forcing } \\
\text { (Intergovernmental Panel on Climate Change 2007) }\end{array}$ \\
\hline Acidification & $\begin{array}{l}\text { Proton release (Hauschild and Wenzel 1998; Huijbregts } \\
\text { 1999) }\end{array}$ \\
\hline Eutrophication & Increased supply of nutrients (Heijungs et al. 1992) \\
\hline Ozone layer depletion & $\begin{array}{l}\text { Release of chloride and bromide ions (World } \\
\text { Meteorological Organization 2010) }\end{array}$ \\
\hline Smog & Tropospheric ozone formation (Guinée et al. 2002) \\
\hline
\end{tabular}

\section{Results of case study}

The results for the three shelves analyzed in section 3 of the manuscript are shown in Table S.3.

Table S.3: Results of the three considered shelves (polypropylene, steel and oak)

\begin{tabular}{|c|c|c|c|c|}
\hline Dimension & Category & $\begin{array}{l}\text { Polypropylene } \\
\text { shelf }\end{array}$ & Steel shelf & Oak shelf \\
\hline & Climate change & 17.5 & 27.9 & 15.3 \\
\hline & Acidification & 2.97E-02 & $9.41 \mathrm{E}-02$ & $3.45 \mathrm{E}-02$ \\
\hline & Eutrophication & $3.71 \mathrm{E}-03$ & $8.50 \mathrm{E}-03$ & 7.11E-03 \\
\hline & Ozone depletion & $1.32 \mathrm{E}-09$ & $6.1 \mathrm{E}-10$ & $6.02 \mathrm{E}-10$ \\
\hline & Smog & $4.85 \mathrm{E}-03$ & $1.21 \mathrm{E}-02$ & $2.20 \mathrm{E}-02$ \\
\hline & $\begin{array}{l}\text { Compliance with social } \\
\text { standards }\end{array}$ & 1.64 & 23.37 & 12.93 \\
\hline & $\begin{array}{l}\text { Compliance with environmental } \\
\text { standards }\end{array}$ & 3.02 & 8.92 & 9.94 \\
\hline & Food security & 0 & 0 & 22.85 \\
\hline & Natural disasters & 182 & 160 & 74.32 \\
\hline & Phosphorus availability & 0 & 0 & 53 \\
\hline & Land availability & 1.15 & 0.92 & 248 \\
\hline & Water availability & 78 & 102 & 51 \\
\hline
\end{tabular}




\begin{tabular}{|c|c|c|c|c|}
\hline \multirow{17}{*}{$\begin{array}{l}\text { Socio-eco- } \\
\text { nomic availa- } \\
\text { bility }\end{array}$} & Company concentration & 51956 & 0 & n.a. \\
\hline & Demand growth & 0 & $8.00 \mathrm{E}+05$ & $2.51 \mathrm{E}+06$ \\
\hline & Trade barriers & 0 & $3.08 \mathrm{E}+06$ & 0 \\
\hline & Political (in) stability & $1.29 \mathrm{E}+06$ & $3.48 \mathrm{E}+06$ & 0 \\
\hline & Occurrence as/of coproduct & 0 & 0 & 0 \\
\hline & Price fluctuation (Variation) & $1.92 \mathrm{E}+06$ & $8.98 E+06$ & 0 \\
\hline & Primary material use (Recycling) & $1.55 \mathrm{E}+06$ & 0 & 0 \\
\hline & $\begin{array}{l}\text { Concentration of } \\
\text { reserves/resources }\end{array}$ & 0 & $3.06 \mathrm{E}+05$ & $3.26 \mathrm{E}+06$ \\
\hline & Concentration of production & 0 & $1.55 \mathrm{E}+06$ & $8.09 E+06$ \\
\hline & Storage capacity & $2.38 \mathrm{E}+00$ & $5.71 \mathrm{E}+00$ & $6.46 \mathrm{E}+04$ \\
\hline & Mining capacity & 0 & $4.68 \mathrm{E}+04$ & 0 \\
\hline & $\begin{array}{l}\text { Feasibility of exploration } \\
\text { projects }\end{array}$ & $1.79 E+06$ & 0 & 0 \\
\hline & Resource depletion - metals & n.t. & $5.61 \mathrm{E}-07$ & n.t. \\
\hline & Resource depletion - biotic & n.t. & n.t. & $1.03 \mathrm{E}-12$ \\
\hline & resource depletion - fossils & 245.51 & n.t. & n.t. \\
\hline & Anthropogenic availability & $5.80 \mathrm{E}-06$ & $8.51 \mathrm{E}-04$ & n.t. \\
\hline & Replenishment rate & 0 & 0 & 5.00E-01 \\
\hline
\end{tabular}

\section{References}

Angerer G, Erdmann L, Marscheider-Weidemann F, et al (2009) Rohstoffe für Zukunftstechnologien Rohstoffe für Zukunftstechnologien. ttps://www.deutsche-rohstoffagentur.de/DERA/DE/Downloads/Studie_Zukunftstechnologien2016.pdf?_blob=publicationFile\&v=3. Accessed Feb 2017

Bach V, Berger M, Finogenova N, Finkbeiner M (2017) Assessing the Availability of Terrestrial Biotic Materials in Product Systems (BIRD). Sustainability 9:137. doi: 10.3390/su9010137

Bach V, Berger M, Henßler M, et al (2016) Integrated method to assess resource efficiency - ESSENZ. J Clean Prod. doi: 10.1016/j.jclepro.2016.07.077

Barrientos M, Soria C (2016) IndexMundi. http://www.indexmundi.com/about.html. Accessed Feb 2016

Berger M, van der Ent R, Eisner S, et al (2014) Water accounting and vulnerability evaluation (WAVE): considering atmospheric evaporation recycling and the risk of freshwater depletion in water footprinting. Environ Sci Technol 48:4521-8. doi: 10.1021/es404994t

British Geological Survey (2014) World Mineral Production. https://www.bgs.ac.uk/mineralsuk/statistics/worldStatistics.html. Accessed Feb 2015

Cervantes M, McMahon F, Wilson A (2013) Survey of Mining Companies: 2012/2013. www.fraserinstitute.org/sites/default/files/miningsurvey-2012-2013.pdf. Accessed Feb 2016

Federal Institute for Geosciences and Natural Resources (2014) Volatilitätsmonitor. http://www.deutscherohstoffagentur.de/DERA/DE/Rohstoffinformationen/Rohstoffpreise/Volatilit\%C3\%A4tsmonitor/volatilit\%C3\%A4tsmonitor nod e.html. Accessed Mar 2015

Food and Agriculture Organization of the United Nations (2016) Food security indicators. http://www.fao.org/economic/ess/essfs/essfadata/en/\#.V2jUO1SLSUn. Accessed Feb 2016 
Graedel TE (2011) UNEP Recycling rates of metals - A Status Report, a Report of the Working Group on the Global Metal Flows to the international Resource Panel.

Guinée JB, Gorrée M, Heijungs R, et al (2002) Handbook on life cycle assessment. Operational guide to the ISO standards. I: LCA in perspective. Ila: Guide. IIb: Operational annex. III: Scientific background.

Guinée JB, Heijungs R, Haes HAU de, Huppes G (1993) Quantitative life cycle assessment of products - 2. Classification, valuation and improvement analysis.

Hanouz MD, Geiger T, Doherty S (2014) The Global Enabling Trade Report 2014. https://www.weforum.org/reports/global-enablingtradereport-2014. Accessed Feb 2016

Hauschild MZ, Wenzel H (1998) Environmental Assessment of Products - Volume 2: Scientific Background. ISBN 978-0-412-80810-4

Heijungs R, Guinée JB, Huppes G, et al (1992) Environmental life cycle assessment of products - guide and backgrounds (Part 2). https://openaccess.leidenuniv.nl/handle/1887/8062. Accessed Mar 2016

Huijbregts M a. J (1999) Life-cycle impact assessment of acidifying and eutrophying air pollutants. http://media.leidenuniv.nl/legacy/Lifecycle\%20impact\%20assessment.pdf. Accessed Mar 2016

Intergovernmental Panel on Climate Change (2007) IPCC Climate Change Fourth Assessment Report: Climate Change. In: IPCC Clim. Chang Fourth Assess. Rep. Clim. Chang. http://www.ipcc.ch/ipccreports/assessments-reports.htm.

Norris CB, Norris G, Aulisio D (2013) Social Hotspots Database. http://socialhotspot.org/.

Oers L van, Konig A de, Guinée JB, Huppes G (2002) Abiotic resource depletion in LCA Abiotic resource depletion in LCA Improving characterisation factors for abiotic ressource depletion as recommended in the new Dutch LCA Handbook.

Organisation for Economic Cooperation and Development (2016) Economic resilience. http://www.oecd.org/economy/growth/economicresilience.htm. Accessed Feb 2016

Rhoades SA (1993) The Herfindahl-Hirschman index. Federal Reserve Bulletin. Volume 79, Issue 3, Pages 188-189

Sas H (1997) Extraction of biotic resources: development of a methodology for incorporation in LCAs, with case studies on timber and fish

Ministerie van Volkshuisvesting, Ruimtelijke Ordening en Milieubeheer, Centrale Directie Voorlichting en Externe Betrekkingen, 1997

Schneider L, Berger M, Finkbeiner M (2011) The anthropogenic stock extended abiotic depletion potential (AADP) as a new parameterisation to model the depletion of abiotic resources. Int J Life Cycle Assess 16:929-936. doi: 10.1007/s11367-011-0313-7

Schneider L, Berger M, Finkbeiner M (2015) Abiotic resource depletion in LCA-background and update of the anthropogenic stock extended abiotic depletion potential (AADP) model. Int J Life Cycle Assess. doi: 10.1007/s11367-015-0864-0

United Nations Office for Disaster Risk Reduction (2013) Global Risk Data Platform. In: Flood events 1999-2007, Droughts events 19802001. http://preview.grid.unep.ch/index.php?preview=data\&events=floods\&evcat=1\&lang=eng. Accessed Feb 2016

United States Geological Survey (2015) Commodity Statistics and Information. http://minerals.usgs.gov/minerals/pubs/commodity/. Accessed May 2004

World Bank Group (2013) The Worldwide Governance Indicators. http://info.worldbank.org/governance/wgi/index.aspx\#home. Accessed Mar 2015

World Meteorological Organization (2010) Scientific Assessment of Ozone Depletion : 2010 Global Ozone Research and Monitoring Project-Report No. 52.

Yale Center for Environmental Law \& Policy (2014) Environmental Performance Index. In: 2014 Environ. Perform. Index. http://epi.yale.edu/. Accessed Mar 2015 